\title{
Analysis on shear distribution of composite box-girder with corrugated steel webs under construction phase
}

\author{
Zheng Guohua ${ }^{1}$, Huang Hao ${ }^{1}$,Wan Shui ${ }^{2, *}$ \\ ${ }^{1}$ Anhui Transport Construction \& Design Institute Co., Ltd, Anhui 230088, CHINA; \\ ${ }^{2}$ School of Transportation, Southeast University, Nanjing 210096, CHINA;
}

Keywords: Shear distribution, corrugated steel web, Construction phase, FEA model.

Abstract. The paper is devoted to the shear force distribution of box girder with corrugated webs. A non-linear finite element software (ABAQUS) was used for simulating cantilever girder under construction phase. We take 8 research sections for analyzing under concentrated load. The results indicate that, from the fixed end to the cantilever end, the shear force ratio of top concrete slab increase gradually, so it to the corrugated webs, while bottom concrete slab shows different regular pattern. Also we find that, at the fixed end, bottom concrete slab takes majority shear force nearly 90 percent, while top concrete slab and corrugated steel webs take only 10 percent, so we should take bottom concrete slab shear design in to consideration under construction phase. In addition, left/mid/right corrugated web take the average corrugated shear force of the total corrugated web shear force. The relative conclusions can be provided as an analysis reference for the similar design.

\section{Introduction}

Bridges with corrugated steel webs have been extensively constructed in different countries due to their notable advantages, especially in Japan and China. At present, Japan has the most of bridges with corrugated steel webs in the world, nearly 200. The use of corrugated steel webs have been considered for a long time to increase the buckling strength and out-of-plane stiffness eliminating the use of vertical stiffeners which have a principal influence on the shear strength of conventionally stiffened flat web [1]. In addition, due to the accordion effect [2,3], the corrugated steel web carries merely shear forces and does not carry any significant normal stress from primary flexural, so it doesn't suffer from bend buckling as well. Consequently, the bending moment is nearly carried by its concrete flanges [4]. It was, however, found that the girder with corrugated steel webs can improve the aesthetics of structure [5].

For a long time, a lot of theoretical analysis and experimental researches on such structure have been conducted by research institutions and universities, such as the ultimate bending strength (e.g., Elgaaly et al), local flange buckling (e.g., Lindner 1992; Protte 1993; Johnson and Cafolla 1997), shear strength (e.g., Elgaaly et al; El-Metwally, Abbas, Sause et al; Driver et al), in-plane shear and flexural behavior have received more research attention. However, in construction application, the corrugated steel web usually bears most of the shear strength while the shear resistance of the concrete flange is neglected, which makes the corrugated steel webs thicker and it may result in a design that is not economical. Therefore, analyses on shear distribution of composite box-girder with corrugated steel webs under construction phase are very important and significant.

This paper describes the investigation carried out on the shear distribution of composite box-girder with corrugated steel webs. The aim of this study is to determine the shear force distribution ratio of concrete slab and corrugated steel webs under construction phase. Calibrated finite element methods were adopted for these purposes.

\section{Elastic shear distribution of composite box-girder with corrugated steel webs}

In the following, a brief discussion about the shear distribution of composite box-girder with corrugated steel webs (top concrete slab, corrugated steel webs, bottom concrete slab) is provided.

2.1. Finite Element Model 
A finite element program, ABAQUS, is used for numerical analyses on composite box-girder with corrugated steel webs (in Fig.1.). Quadrangle/Hexahedral mesh grids are structured by combined using the software of ABAQUS and HYPERMESH. Throughout the analyses, C3D8I incompatible element type were used for modeling solid concrete, and S4 element type were used for modeling corrugated steel webs. To simulate the construction phase accurately, symmetric boundary condition was adopted at the center line of the bridge piers, and the vertical temporary constraint were installed at the bottom of zero block (in Fig.2.).

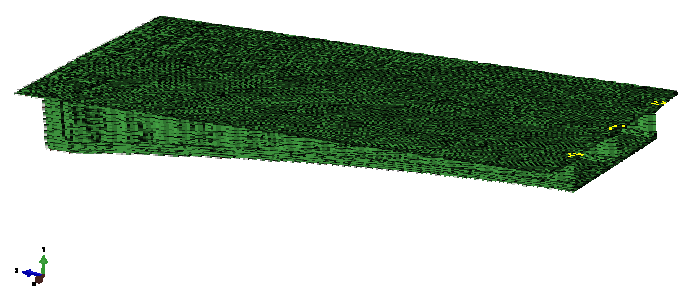

Figure1. FEA model

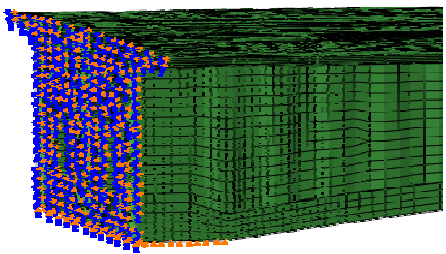

Figure2. Boundary condition of FEA model

The FEA model was divided into 12 segments from bridge pier to mid-span; at the end of each segment we set research section, such as section1, section 2, etc.

2.2. Results and discussion

To simulate the construction phase of box-girder with corrugated steel webs, we'll apply concentrated loads to replace hanging basket weight; the load will be set at the end of cantilever. It's not necessary to simulate the actual weight of hanging basket in case the whole model is in elastic phase. Due to the influence of stress concentration, we'll not take sections, such as section1, section10, section11, section12, into account. The shear force were extracted by creating a free body cut in ABAQUS, and top concrete slab, bottom concrete slab, corrugated steel webs' shear force distribution ratio are given in Fig. 3, also left corrugated webs, mid corrugated web and right corrugated web's shear force distribution ratio are given into Fig. 4 too.

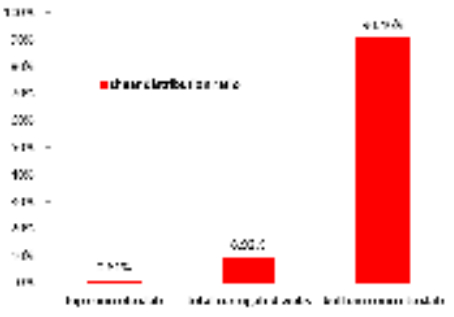

(a) Section2

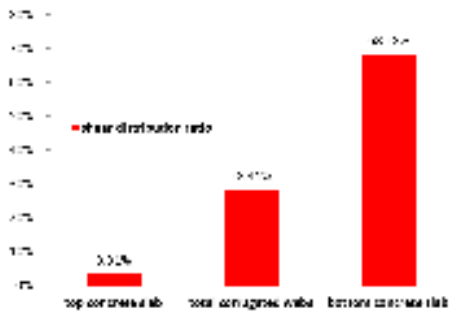

(d) Section5

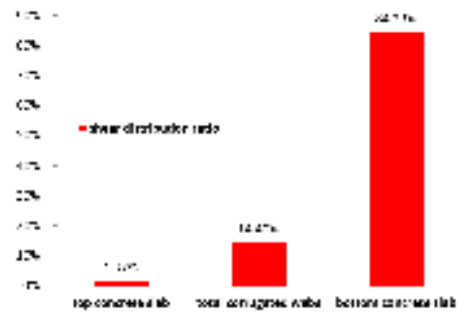

(b) Section3

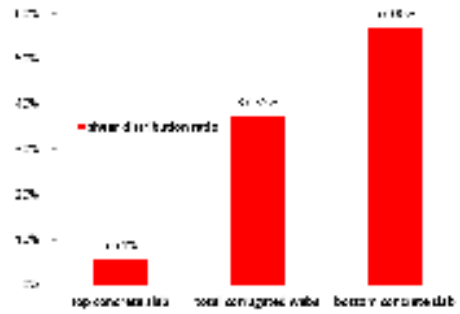

(e) Section6

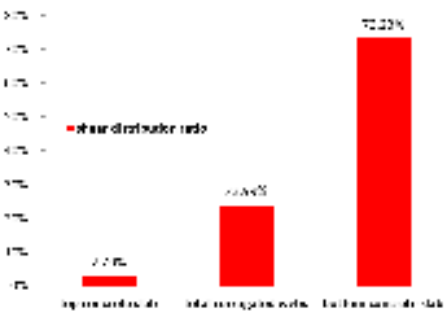

(c) Section4

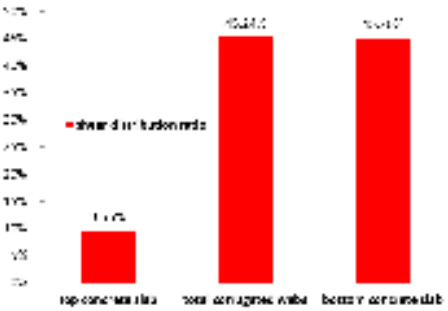

(f) Section7

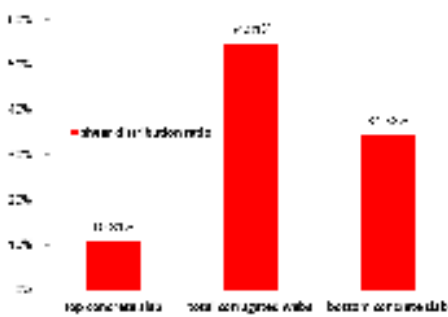

(g) Section8

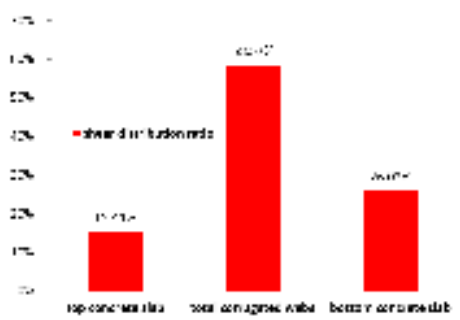

(h) Section9

Figure3. Shear distribution ratio of top/bottom concrete slab and corrugated webs 
As we can see from Fig.3, with the research section change, shear force ratio of top/bottom concrete slab and corrugated webs change too. From section 2 to section9 (also we can say from the fixed end to the cantilever end), the shear force ratio of top concrete slab increase gradually, so it to the corrugated webs, while bottom concrete slab shows different regular pattern. At the fixed end (section2), bottom concrete slab takes majority shear force nearly 90 percent, while top concrete slab and corrugated steel webs take only 10 percent, but at the cantilever end (section9), corrugated webs takes more than half shear force, top and bottom concrete slab takes the others. So under the construction stage, we should pay more attention to the the bottom concrete slab's shear ability instead of corruated webs only, this is what current design lack of. On the contrary, the design of corrugated webs shear ability is safe and abundant.

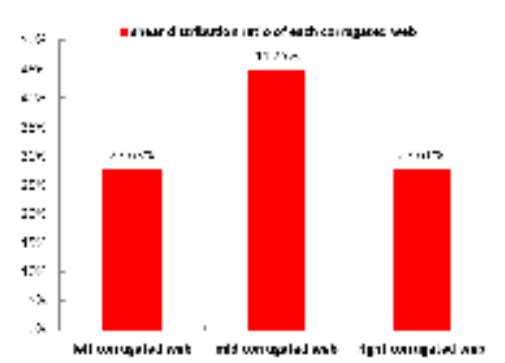

(a) Section2

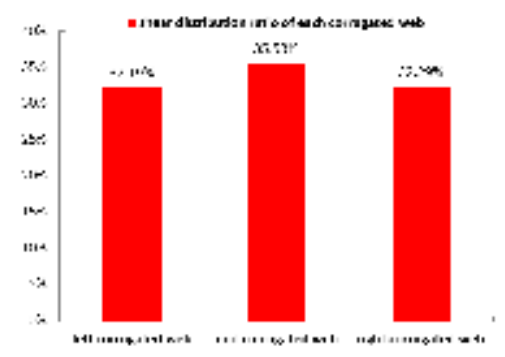

(d) Section5

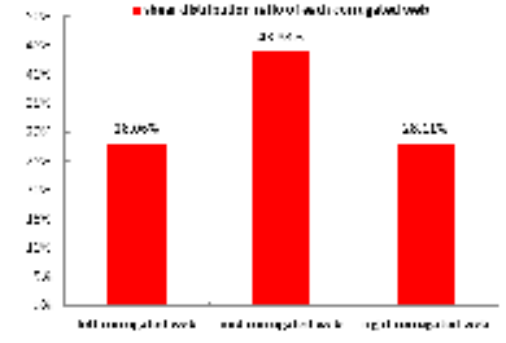

(b) Section 3

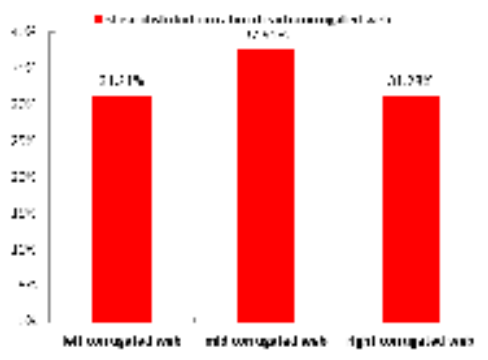

(e) Section6

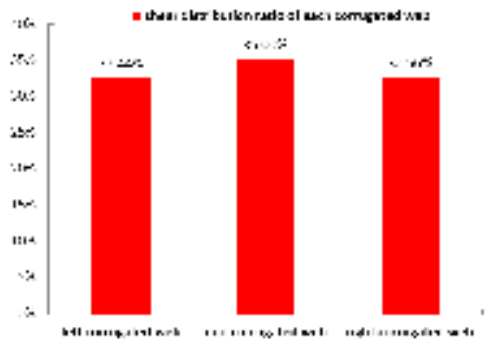

(c) Section 4

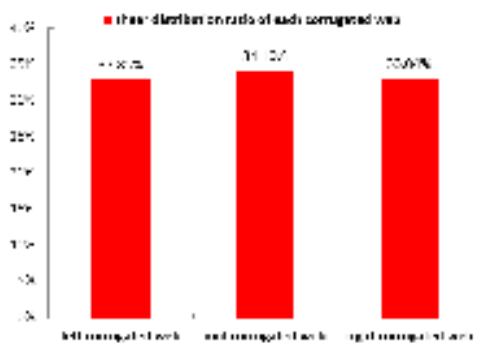

(f) Section7

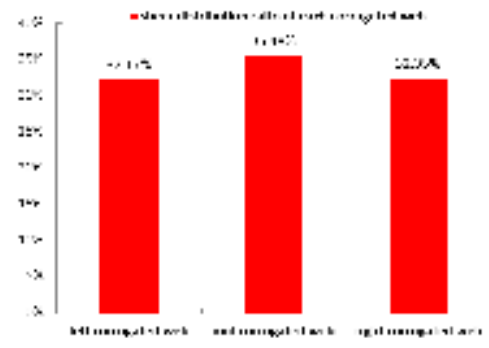

(g) Section 8

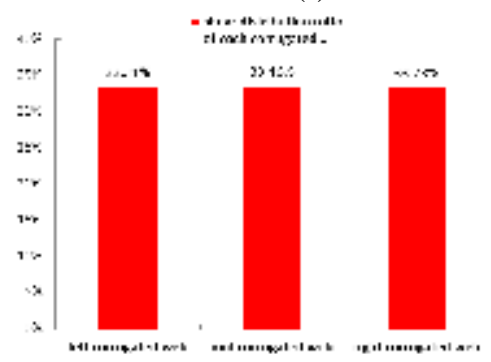

(h) Section 9

Figure4. Shear distribution ratio among left/mid/right corrugated web

According to Fig.4, we find out that, even if corrugated webs' shear force changes with its section location as a whole in Fig.3, however, among corrugated webs, left/mid/right corrugated web take the average corrugated shear force as part, the condition near the fixed end is an exception, this is because cross slope on top concrete slab exists. The higher you are, the more you'll bear. Current design always divide the whole shear force into $\mathrm{n}$ ( $\mathrm{n}$ is the number of corrugated webs), we know that this is the right way to do so.

\section{Summary and Conclusions}

In this investigation, the shear force distribution of box girder with corrugated webs has been studied computationally. A non-linear finite element software (ABAQUS) was used for these purpose, comparisons of results were also made by comparing different sections to evaluate the shear force distribution of box girder with corrugated webs. The results show that shear force ratio of top/bottom concrete slab and corrugated webs change with the research section change, the general rule is, from the fixed end to the cantilever end, the shear force ratio of top concrete slab increase gradually, so it to 
the corrugated webs, while bottom concrete slab shows different regular pattern. At the fixed end, bottom concrete slab share the majority shear force of the whole section, which means that we should take bottom concrete slab shear design in to consideration under construction phase. In addition, left/mid/right corrugated web take the average corrugated shear force of the total corrugated web shear force.

\section{Acknowledgements}

The research described in this paper was funded by the Fuyang highway administration. The support provided by Southeast University, is very much appreciated.

\section{References}

[1] M.F.Hassanein, O.F. Kharoob. Behavior of bridge girders with corrugated webs: (I) Real boundary condition at the juncture of the web and flanges. Engineering Structures 2013; 57:554-564

[2] Driver RG, Abbas HH, Sause R. Shear behavior of corrugated web bridge girders. J Struct Eng, ASCE 2006; 132(2):195-203

[3] Hamilton RW. Behavior of welded girder with corrugated webs. Ph.D. thesis. University of Maine; 1993.

[4] Moon J, Yi J-W, Choi BH, Lee H-E. Lateral-torsion buckling of girder with corrugated webs under uniform bending. Thin-Walled Struct 2009; 47:21-30.

[5] Elgaaly M, Hamilton RW, Seshadri A. Shear strength of beam with corrugated webs. J Struc Eng 1996; 122(4):390-8.

[6] Hassan H. Abbas, Richard Sause, Robert G. Driver. Behavior of Corrugated Web I-Girders under In-Plane Loads. J. Eng. Mech.,2006, 132(8):806-814 